\title{
Desenvolvimento de Solução IoT para Sensoriamento Hídrico em Tempo Real
}

\author{
Jorge Otta Júnior \\ Universidade Tecnológica Federal do Paraná \\ Toledo, PR \\ tamahome14@gmail.com
}

Augusto Vaghetti Luchese

Universidade Federal do Paraná

Palotina, PR

aluchese@gmail.com

\author{
Leandro Augusto de Carvalho \\ Universidade Tecnológica Federal do Paraná \\ Toledo, PR \\ leandro.carvalho89@gmail.com \\ Pedro Luiz de Paula \\ Univesidade Tecnológica Federal do Paraná \\ Medianeira, PR \\ plpf2004@gmail.com
}

\begin{abstract}
The continuos increase in the world population causes higher use of natural resources for their maintenance, one of which is water. The article caries out a study of the mechanics of water infiltration and retention in the soil using sensors to try and maximize the use of water in agriculture and to evaluate other hydric characteristics of the soil. Calibration procedures were performed in a controlled environment based on the standard greenhouse method readings. This work have used an equipment built at low cost enabling the reproduction of the results achieved by the community of developers and researchers interested in continuing the presented work. It was possible to calibrate the sensors, enabling measurement in a controlled study environment. The collected data provided preliminary information on the infiltration and water retention of the three soils studied.
\end{abstract}

Resumo - O crescente aumento da população mundial provoca aumento no uso dos recursos naturais para sua manutenção, sendo um deles, o hídrico. $O$ objetivo deste artigo é realizar um estudo das mecânicas da infiltração e retenção hídrica no solo por meio de sensores para maximizar o uso de água na agricultura e avaliar outras características hídricas do solo. Foram realizados procedimentos de calibração em ambiente controlado baseado nas leituras do método padrão de estufa. $O$ artigo utilizou-se de equipamentos construídos a baixo custo que possibilitarão a reprodução dos resultados alcançados pela comunidade de desenvolvedores e pesquisadores interessados na continuidade do trabalho apresentado. Foi possível realizar a calibragem dos sensores de umidade possibilitando medição em ambiente controlado. Os dados coletados possibilitaram informações preliminares sobre a infiltração e retenção hídrica dos três solos estudados.

Palavras-chave-Umidade do solo; monitoramento; arduíno.

\section{INTRODUÇÃO}

A umidade do solo, variável ambiental, hídrica e climática essencial, afeta fortemente os fluxos de água na superfície do solo com impactos na temperatura e evapotranspiração [1]. A interação entre a atmosfera e umidade do solo tem recebido, em anos recentes, crescente atenção na pesquisa do clima [2].

Determinando o balanço de água na zona das raízes e a mecânica de infilltração de água no solo, é possível também determinar a velocidade e eficiência que as culturas plantadas absorvem nutrientes para crescimento. Nota-se uma crescente necessidade de otimização no uso dos recursos hídricos disponíveis considerando-se as crises hídricas reportadas na conjuntura, relatório de responsabilidade da Agência Nacional das Águas (ANA), de acordo com a Resolução n ${ }^{\circ}$ 58/2006. Entre os anos de 2012 e 2016, a bacia do São Francisco enfrentou forte seca, sendo que em 2015, esse reservatório, do Tocantins-Araguaia e das demais regiões hidrográficas tiveram os menores índices do período [3]. Outro motivo de preocupação é a bacia do São Francisco ser umas das 3 bacias componentes do Sistema Interligado Nacional (SIN) que totalizam 266 bilhões de $\mathrm{m}^{3}$, cerca de $88 \%$ da capacidade de armazenamento do SIN [3]

A demanda pelo uso de água no Brasil é crescente, com aumento estimado de aproximadamente $80 \%$ no total retirado de água nas últimas duas décadas e com previsão de aumento de $30 \%$ até 2030 [3]. Exigindo grande uso de recursos hídricos para produção de alimentos e eletricidade, especialmente no Brasil, um país com grande parte de sua energia produzida por hidrelétricas, com $64,5 \%$ da matriz elétrica [3].

De acordo com o Conjuntura de 2017, relatório anual de elaboração de responsabilidade da ANA, 67,2\% da vazão média de consumo de $1.109 \mathrm{~m}^{3} \mathrm{~s}^{-1}$ são consumidos pela irrigação. A atividade agropecuária no Brasil tem importante papel para a economia do país. Particularmente diversas culturas têm projeção de crescimento, $3,3 \%$ do algodão em pluma e arroz, 1,4\%, milho, 1,7\%, trigo, 1,2\%, soja, $2,3 \%$ e café, $4,4 \%$ ao ano até 2022, segundo o Ministério da Agricultura, Pecuária e Abastecimento [4].

Visando o fornecimento de informações acerca das condições hídricas do solo, este artigo utiliza um protótipo constituído por um conjunto de sensores de baixo custo para realizar estudo sobre a infiltração e retenção de água em três amostras de textura de solo diferentes em tempo real e em ambiente controlado.

\section{MATERIAL E MÉTODOS}

O método da estufa é utilizado como método padrão e de referência para realizar a medição do conteúdo gravimétrico da água no solo e consiste em deixar uma quantidade de material com peso conhecido secando em estufa por um período entre 24 e 48 horas a uma temperatura entre 105 e $110^{\circ} \mathrm{C}$. A diferença entre o peso do material úmido e o seco é o peso da umidade que estava contida no material analisado [5] de acordo com a equação 1 , onde $\mathrm{Mu}$ é o peso da amostra úmida e Ms é o peso da amostra seca:

$\%$ Umidade $=((\mathrm{Mu}-\mathrm{Ms}) / \mathrm{Ms}) .100$ 
Equação 1 - Fórmula para obtenção da porcentagem de umidade gravimétrica

As principais vantagens desse método são a integridade estrutural da amostra analisada e a alta confiabilidade na medição obtida além da aplicabilidade para diversos materiais a serem estudados. A grande demora ( 24 a 48 horas) para obtenção de qualquer leitura e seu caráter destrutivo, não permitindo sua repetibilidade em uma mesma amostra, são suas principais desvantagens.

Objetivando agilizar a leitura desse importante parâmetro do solo, diversos sensores foram desenvolvidos de modo a realizar a leitura de outro parâmetro como resistência elétrica, capacitância ou pressão, e relacioná-lo com a umidade do solo utilizando leituras obtidas pelo método padrão da estufa [5]. Segundo Silva et al (2008)[6] para aumentar o nível de precisão é necessário realizar calibrações para adaptar as leituras do sensor ao ambiente em que será utilizado.

Sensores industriais como os citados podem custar R\$ 4.000,00 reais e suas unidades armazenadoras (datalogger) R\$ $3.000,00$ adicionais na data de realização deste estudo $(15 / 06 / 2018)$.

Foram considerados os microcontroladores Arduino e Raspberry como possíveis armazenadores e coletores de dados. Arduino foi lançado como uma plataforma de desenvolvimento livre, composto basicamente de um micro controlador com entradas e saídas digitais e analógicas. A escolha por este micro controlador como coletor de dados foi em decorrência do conversor analógico-digital integrado à placa que permite a leitura de sinais analógicos sem a adição de componentes adicionais. Como armazenador de dados, optou-se pelo uso de um Raspberry PI com um disco rígido conectado pela porta USB, pela vantagem de utilização do ambiente de desenvolvimento integrado ao Sistema Operacional recomendado.

O esquemático da conexão dos componentes encontra-se na figura 1. Entrada analógica 6 a 15 para os sensores de umidade de solo. Saídas 22 a 4, em pares, para cada sensor. Entradas PWM 6 a 9 para os sensores DS18B20. A alimentação e comunicação entre o Arduino e o Raspberry foi realizada por um cabo USB e os dados foram transmitidos utilizando o protocolo serial.

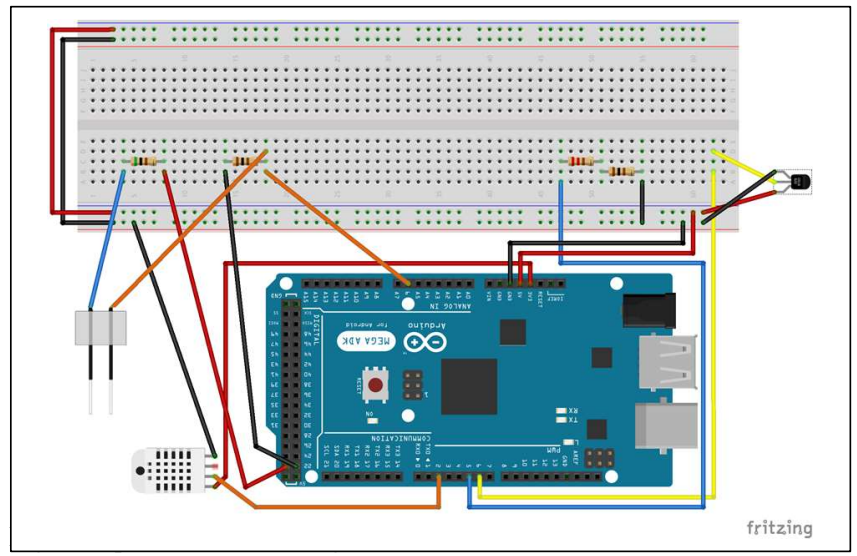

Fig. 1 Esquemático da conexão dos componentes

Os sensores DHT22 foram utilizados para verificar possível correlação entre as leituras obtidas pelos sensores e a umidade e temperatura locais quando da calibração. Os sensores DS18B20 foram utilizados para verificar se há mudança de temperatura causada pelo processo de calibração utilizado para os solos estudados.

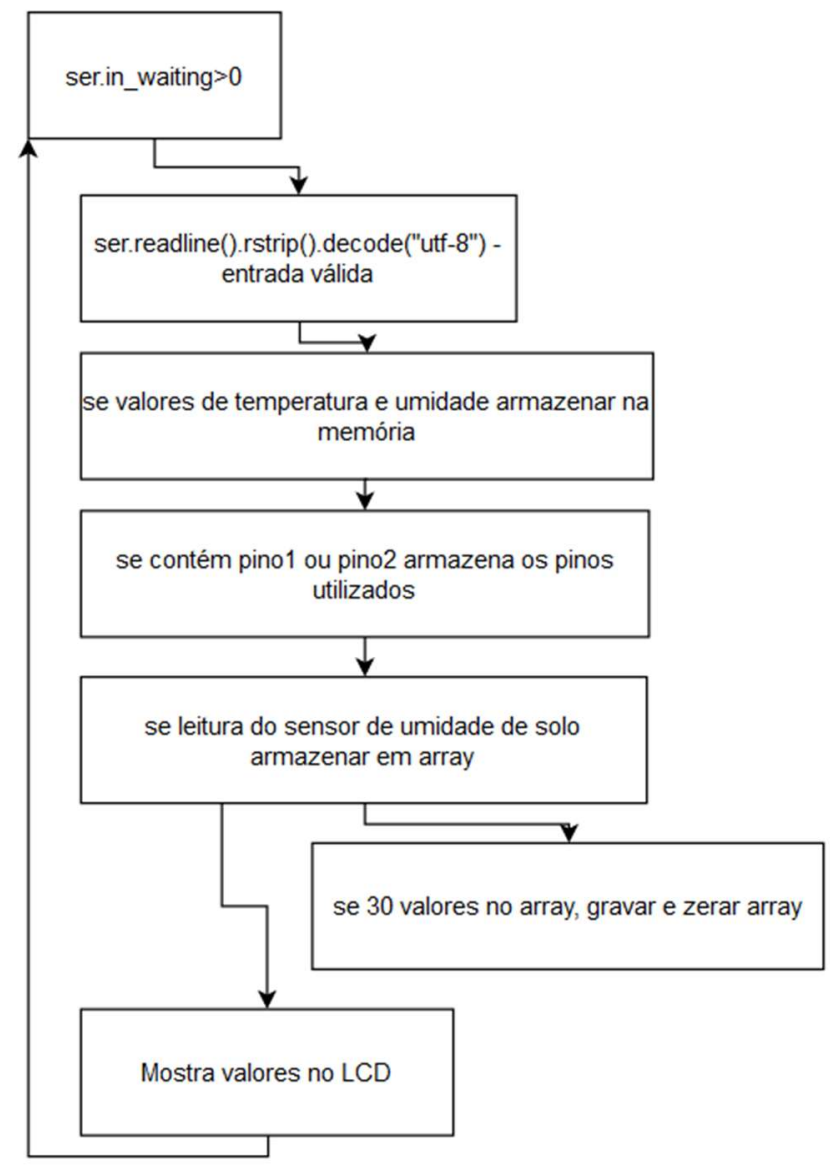

Fig. 2 Diagrama do código executado no Raspberry PI

A figura 2 apresenta o pseudocódigo executado no Raspberry. Aguarda-se que o status in waiting mude para maior que zero para então verificar se são dados válidos a serem armazenados. Se forem valores de temperatura e umidade ou os pinos utilizados na leitura, são armazenados na memória em variáveis simples. Se for leitura de um sensor de umidade de solo, os valores são armazenados em um array. Assim que esse array atinge 30 registros, seu conteúdo é armazenado em arquivo em mídia não volátil e zerado. Após essas verificações, os valores lidos são apresentados em um LCD para visualização pelo operador.

A rotina principal executada no Arduino é a leitura do sensor de umidade de solo e está apresentada na sequência abaixo:

- seta direção de leitura do sensor (do pino de ID menor para o maior)

- espera $100 \mathrm{~ms}$

- leitura pela porta analógica

- espera $100 \mathrm{~ms}$

- seta direção de leitura invertida

- espera $100 \mathrm{~ms}$

- leitura pela porta analógica e seu valor subtraído de 1023 (1)

- espera $100 \mathrm{~ms}$

- desativa os dois pinos do sensor de umidade de solo 
A pausa entre cada passo foi adicionada para evitar que a rotina executasse rápido demais e causasse possível alteração no solo estudado. Como a leitura é realizada nos dois sentidos (do pino de ID menor para o maior e vice-versa), o passo (1) subtrai o valor lido de 1023 para o sentido invertido de modo a possibilitar a média dos valores lidos pelo sensor de umidade de solo.

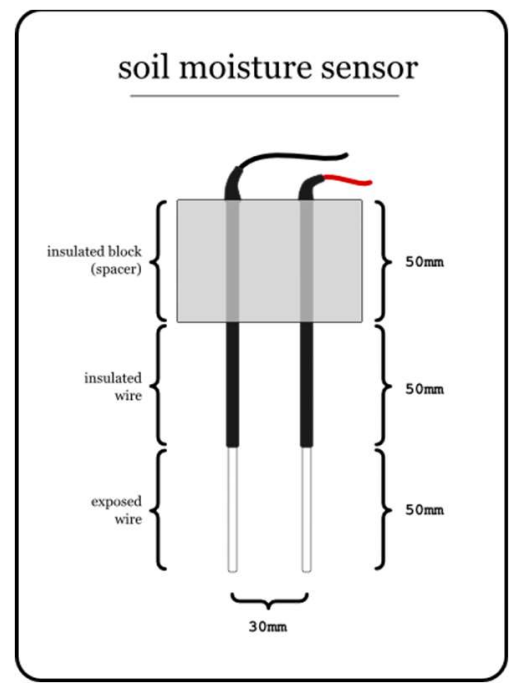

Fig. 3 Esquemático do senso de umidade de solo

Fonte: gardenbot.org

O esquemático do sensor utilizado está representado na figura 3 e é do tipo resistivo. Foram utilizados dois segmentos de arame galvanizado de 12 gauges cujas pontas foram conectadas às portas do Arduino. Os valores, obtidos pelas portas analógicas em uma escala de 0 a 1023 , portanto em uma resolução de 10 bits, quantificam a variação da passagem de corrente elétrica entre as pontas do sensor e a média dos valores medidos nos dois sentidos foram utilizadas para correlação com a umidade pelo método padrão. De modo a diminuir as incertezas nas medições dos sensores, o processo de calibração foi padronizado e repetido três vezes para cada sensor utilizando três amostras de solo com texturas diferentes.

O processo de coleta de dados para a calibração seguiu as instruções constantes na NBR 6457:2016, da ABNT, em especial sobre a quantidade de material em massa seca a tomar. O processo de calibração foi baseado também no método utilizado por Pizetta[7], descrito por Kinzli [8] e citado por Spelman et al [9]. Um quilo de amostra a umidade higroscópica foi lentamente umedecido até o nível de saturação. A quantidade de água necessária foi aferida e utilizada como referência para o valor máximo que os sensores deveriam registrar.

Foram utilizadas duas garrafas pet de 2,5 litros cortadas ao meio para acondicionar a amostra para realização das leituras de calibração de modo a padronizar a distribuição da amostra evitando que diferenças na compactação e distribuição da amostra causassem leituras díspares para a mesma amostra. Para cada rodada, foi utilizado um quilo de cada amostra para determinação do nível $100 \%$ de saturação. Separou-se um litro de água destilada que foi despejada na amostra lentamente de modo a evitar compactação na superfície da amostra. Quando a amostra ficava visualmente a $100 \%$ de saturação, o peso da amostra e da água inserida era aferido. Se durante a meia hora seguinte a amostra não apresentasse visualmente $100 \%$ de saturação, mais água era despejada na amostra.

Os solos estudados foram coletados na região de ToledoPR e Palotina - PR, de texturas muito argilosa, argilosa e média. A amostra muito argilosa foi coletada na posição longitude $24^{\circ} 43^{\prime} 58.9^{\prime \prime} \mathrm{S}$ e latitude $53^{\circ} 45^{\prime} 53.0^{\prime \prime} \mathrm{O}$, e as amostras argilosa e média, nas $24^{\circ} 11^{\prime} 19.2^{\prime \prime S} 53^{\circ} 47^{\prime} 44.6^{\prime \prime} \mathrm{W}$ e $24^{\circ} 11^{\prime} 33.4^{\prime \prime} \mathrm{S} 53^{\circ} 48^{\prime} 30.8^{\prime \prime} \mathrm{W}$ respectivamente.

\section{RESUlTAdOS E DiscUSSÃO}

Após a coleta de dados da calibração dos sensores, procedeu-se um estudo estatístico acerca destes. Calculou-se a estatística descritiva de modo a verificar as características dos dados obtidos para a calibração dos sensores e sua correlação com a umidade obtida pelo método padrão de estufa.

Nota-se pela tabela 1, ilustrando os desvios gerais padrão, variância e coeficientes de variação, que com o aumento do teor de umidade inserido, o coeficiente de variação diminui e os valores de leitura variam menos do valor médio das leituras amostrais. Esperava-se que a variância acompanhasse o coeficiente de variação, porém a maior variância foi verificada para os níveis com maiores teores de umidade. Da mesma forma, os desvios gerais padrão foram menores para os níveis de saturação de 0 a 20 , enquanto para os outros níveis de saturação os desvios foram maiores chegando a 98,38 para $40 \%$ de saturação para a textura argilosa.

Tabela 1

Desvio geral padrão, variância geral e coeficiente de variação dos níveis de umidade 0 a 100 para os três solos de textura diferenciada estudados. MA Muito argiloso, Arg - Argiloso e Média

\begin{tabular}{|l|l|l|l|l|}
\hline Nivel & Solo & $\begin{array}{l}\text { Desvio } \\
\text { Geral }\end{array}$ & Variância & $\begin{array}{l}\text { Coef. } \\
\text { Variação (\%) }\end{array}$ \\
\hline 0 & MA & 4,38 & 19,26 & 278,70 \\
\cline { 2 - 5 } & Arg & 3,42 & 11,73 & 253,37 \\
\cline { 2 - 5 } & Média & 6,19 & 38,30 & 271,98 \\
\hline \multirow{4}{*}{20} & MA & 6,65 & 44,24 & 85,53 \\
\cline { 2 - 5 } & Arg & 3,42 & 11,73 & 50,67 \\
\cline { 2 - 5 } & Média & 17,87 & 319,19 & 10,77 \\
\hline 40 & MA & 13,60 & 184,89 & 29,90 \\
\cline { 2 - 5 } & Arg & 98,37 & 9677,17 & 19,19 \\
\cline { 2 - 5 } & Média & 69,01 & 4763,05 & 9,65 \\
\hline 60 & MA & 37,86 & 1433,60 & 9,35 \\
\cline { 2 - 5 } & Arg & 31,84 & 1013,70 & 3,90 \\
\cline { 2 - 5 } & Média & 38,37 & 1472,54 & 4,60 \\
\hline 80 & MA & 43,53 & 1894,67 & 6,98 \\
\cline { 2 - 5 } & Arg & 24,32 & 591,67 & 3,45 \\
\cline { 2 - 5 } & Média & 44,01 & 1937,06 & 6,49 \\
\hline \multirow{3}{*}{100} & MA & 37,37 & 1392,36 & 4,86 \\
\cline { 2 - 5 } & Arg & 28,68 & 822,35 & 4,77 \\
\cline { 2 - 5 } & Média & 27,61 & 762,47 & 4,62 \\
\hline
\end{tabular}

Construiu-se boxplot de todos os níveis de saturação para as 3 texturas de modo a avaliar a existência de pontos discrepantes. Os pontos discrepantes foram mais frequentes nos níveis de umidade de 0 a 40 , sendo muito numerosos para os três solos estudados para o nível 0 .

Nota-se pela figura 4 ilustrando o boxplot das leituras registradas ao nível de $0 \%$ de saturação que para esse nível, o sensor terá dificuldade de registrar os valores reais de umidade para os níveis próximos devido à grande quantidade de 
outliers encontrados e à alta variância e coeficiente de variação para esse nível de saturação de umidade para as três texturas.

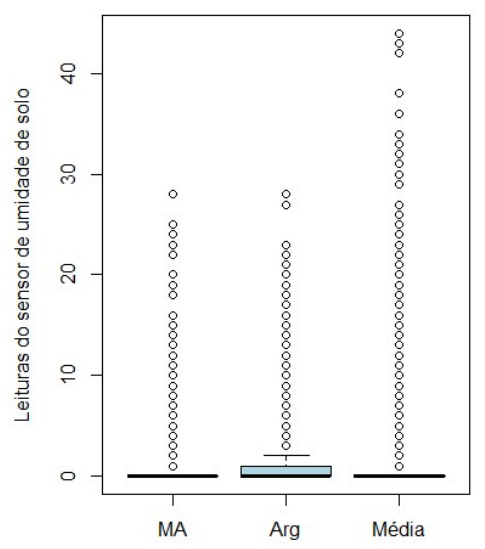

Fig. 4 Boxplot das três texturas de solo estudadas ao nível de $0 \%$ de saturação. Da esquerda para direita: MA - muito argilosa, Arg - argilosa e Média - media

Nota-se pelos bloxplots, ilustrados na figura 5 , que ao nível de $20 \%$ de saturação, a variabilidade das leituras é aproximadamente a mesma para as texturas muito argilosa e argilosa, porém é bem alta para a textura média e por isso, espera-se uma maior variabilidade nas leituras para essa textura quando da coleta de dados em condições similares às encontradas no campo. Para esse nível de saturação a distribuição das leituras é aparentemente normal.

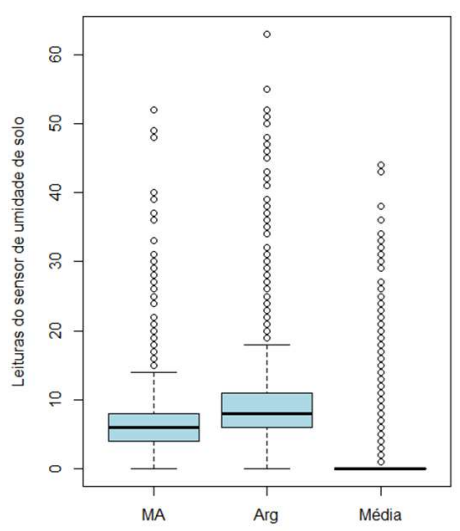

Fig. 5 Boxplot das três texturas de solo estudadas ao nível de $20 \%$ de saturação. Da esquerda para direita: MA - muito argilosa, Arg - argilosa e Média - media

A figura 6, mostra que ao nível de $40 \%$ de saturação grande variabilidade nas leituras para as texturas argilosa e média sendo que para a argilosa, houve uma maior distribuição para os valores menores que a mediana. A textura muito argilosa tem uma distribuição com menor variabilidade e aparentemente do tipo normal.

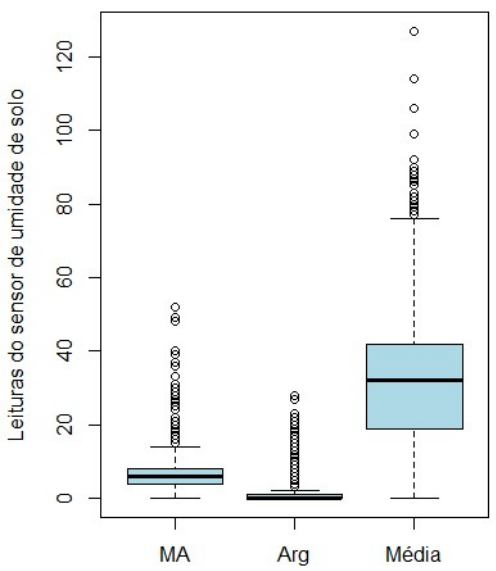

Fig. 6 Boxplot das três texturas de solo estudadas ao nível de $40 \%$ de saturação. Da esquerda para direita: MA - muito argilosa, Arg - argilosa e Média - media

Analisando ao nível de $60 \%$ de saturação, ilustrado na figura 7, nota-se grande amplitude nos valores lidos para a textura muito argilosa com uma proporção maior de valores maiores que a mediana. Os valores lidos nas texturas argilosa e média apresentaram menor amplitude na variação dos seus valores.

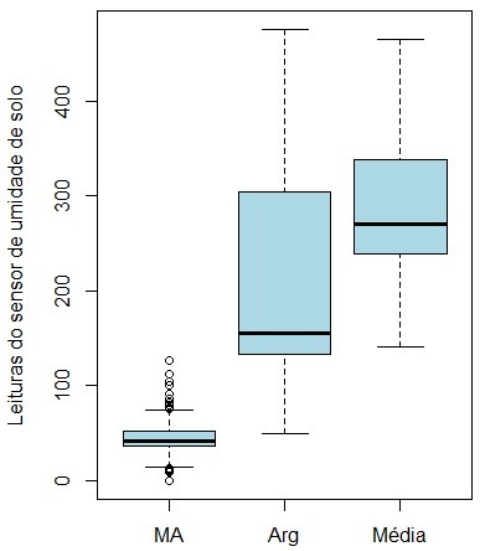

Fig. 7 Boxplot das três texturas de solo estudadas ao nível de $60 \%$ de saturação. Da esquerda para direita: MA - muito argilosa, Arg - argilosa e Média - media

Ao nível de $80 \%$ de umidade, ilustrado na figura 8 , o boxplot da textura argilosa apresentou distribuição normal enquanto a textura muito argilosa e a média, apresentaram distribuição tendendo a valores maiores e menores que a mediana, respectivamente.

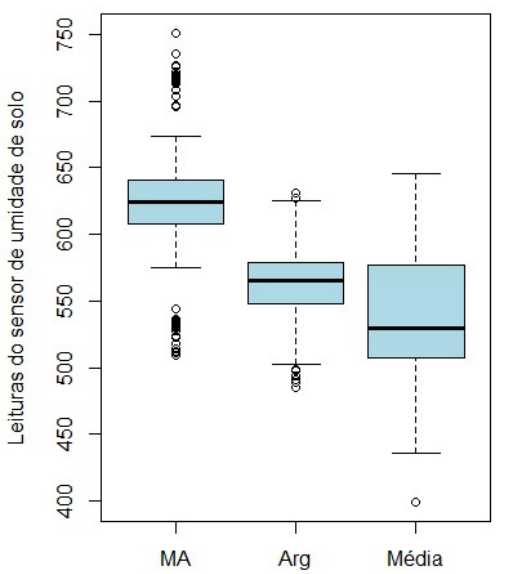


Fig. 8 Boxplot das três texturas de solo estudadas ao nível de $80 \%$ de saturação. Da esquerda para direita: MA - muito argilosa, Arg - argilosa e Média - media

A $100 \%$ de saturação, ilustrada na figura 8 , as leituras da textura muito argilosa apresentaram acentuada variabilidade com a maior parte de seus valores tendendo a serem menores que a mediana. As leituras das texturas argilosa e média apresentaram menor variabilidade sendo que a textura média apresentou valores perto do ideal, com pouca variabilidade e com a maior parte de seus valores perto da mediana.

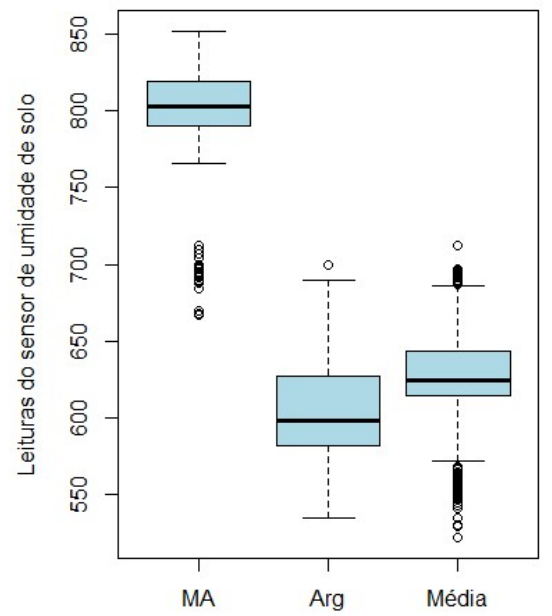

Fig. 9 Boxplot das três texturas de solo estudadas ao nível de $100 \%$ de saturação. Da esquerda para direita: MA - muito argilosa, Arg - argilosa e Média - media

Nota-se pelas figuras 4 a 9 que inicialmente a variabilidade das texturas muito argilosa e argilosa foram parecidas e bem baixas enquanto a variabilidade da textura média foi bastante ampla. Enquanto a textura argilosa apresentou variabilidade menor entre os níveis de umidade, exceto a $40 \%$ de umidade, a textura média apresentou menor variabilidade a níveis mais altos de umidade, a textura muito argilosa apresentou variabilidade menor para as umidades mais baixas.

Acredita-se que esse comportamento tenha relação com a quantidade de água necessária para atingir o nível de 100\% de saturação. Enquanto que para as texturas muito argilosa e argilosa foram usados $520 \mathrm{~mL}$ e $507 \mathrm{~mL}$ de água, para a textura média foram usados somente $392 \mathrm{~mL}$ de água. A tabela 2 mostra a quantidade de água usada para cada nível de saturação.

Tabela 2 - Quantidade de água necessária para atingir os níveis de saturação para as texturas estudadas

\begin{tabular}{|l|l|l|l|}
\hline Nivel & Muito argilosa $(\mathrm{mL})$ & Argilosa $(\mathrm{mL})$ & Média $(\mathrm{mL})$ \\
\hline 20 & 104 & 101,4 & 78,4 \\
\hline 40 & 208 & 202,8 & 156,8 \\
\hline 60 & 312 & 304,2 & 235,2 \\
\hline 800 & 416 & 405,6 & 313,6 \\
\hline 100 & 520 & 507 & 392 \\
\hline
\end{tabular}

Embora a variabilidade nas leituras pareça excessiva, é importante considerar que as amostras utilizadas foram homogeneizadas utilizando uma peneira de $2 \mathrm{~mm}$ de malha, como executado por Predevello \& Loyola, 2005[10], e, portanto, com uma tendência a criar macroporos com uma variabilidade e frequência maiores do que uma de abertura menor. Ademais devido à natureza do sensor devemos optar entre duas opções ao realizar sua calibração:
Homogeneizar a amostra entre as trocas de sensores visando evitar que os sucessivos furos provocados pelo sensor criem alterações na estrutura da amostra, porém com a consequência de alterar sua estrutura e, portanto, os valores de leitura. Essa constante homogeneização provocará ainda a expulsão da umidade causada pela constante manipulação da amostra para níveis mais altos de umidade, para este estudo, igual ou acima de $80 \%$ de saturação;

$\mathrm{Ou}$ não homogeneizar a amostra visando manter a estrutura original criada para evitar que a constante manipulação da amostra cause os empecilhos mencionados anteriormente. Isso, porém, causará dificuldades quando a amostra estiver suficientemente úmida para se sustentar e os constantes furos para inserção dos sensores e leitura acabarão por alterar a estrutura original devido aos sulcos criados.

Neste estudo optou-se pela segunda opção mantendo uma boa variabilidade na amostra, porém sem causar alterações na umidade absorvida pela amostra entre a inserção dos sensores para calibração.

Como os sensores serão usados ao longo do cano na coleta de dados laboratorial, é necessário certificar-se que eles sejam suficientemente parecidos de modo que as leituras possam ser comparadas ao longo do perfil de solo. Realizar essa verificação na fase de calibração garante que os dados coletados nos diferentes níveis da coluna de solos possam ser comparados entre si já que se saberá de antemão que os sensores funcionam de modo análogo.

Um dos testes possíveis de se realizar é o teste de Tukey que compara todos os possíveis pares de médias e se baseia na diferença mínima significativa. Para ser realizado, as seguintes suposições devem ser verdadeiras:

- As observações são independentes dentro e fora dos grupos;

- Os grupos devem ser normalmente distribuídos;

- A variância dentro do grupo deve ser constante.

Utilizou-se o teste de Shapiro-Wilk para verificar se os valores de leitura eram normalmente distribuídos, porém para todos os níveis de saturação e texturas a distribuição foi classificada como não normalmente distribuídas. Sendo assim, utilizou-se um teste não-paramétrico para verificar se as leituras possuíam funções de distribuição iguais.

A tabela 3 mostra o p-valor resultante do teste de Kruskal para os diversos níveis de saturação e solos. Valores menores que um nível de significância de 5\% resulta em rejeição da hipótese zero, de que não há diferença significativa entre os sensores.

Tabela 3 - P-valores para os níveis de saturação de zero e 20 a cem para as três texturas estudadas

\begin{tabular}{|l|l|l|}
\hline & 0 & $20-40-60-80-100$ \\
\hline MA & 0,01561 & $2,2 \mathrm{e}-16$ \\
\hline Argilosa & 0,1715 & $2,2 \mathrm{e}-16$ \\
\hline Média & $2,01 \mathrm{e}-$ & $2,2 \mathrm{e}-16$ \\
\hline
\end{tabular}

Nota-se que somente a $0 \%$ de saturação e para a textura argilosa os sensores são semelhantes. Porém deve-se notar que para o nível zero de saturação os pontos considerados discrepantes foram os maiores que 1 para essas texturas e, portanto, essa semelhança era esperada. 
Considerando a diferença entre as leituras obtidas pelos sensores na grande maioria dos níveis de saturação e texturas, a coleta de dados no cano utilizará as médias de leituras para os cálculos seguintes. Embora durante o processo de calibração notou-se que os valores de desvio padrão e desvio médio das leituras para cada nível de calibração e sensor e na mesma repetição, mantiveram-se abaixo de $9 \%$ e $5 \%$ respectivamente, melhorando conforme o nível de umidade medido, chegando a menos de $5 \%$ e $3 \%$ respectivamente. Considerando o custo para sua construção, para níveis de saturação acima de $25 \%$ para as texturas argilosa e média e de $30 \%$ para a textura muito argilosa, os sensores apresentaram valores satisfatórios de leitura.

Devido aos valores dos sensores de umidade do solo serem afetados pelos diversos fatores mencionados anteriormente, optou-se por, nesse estudo, utilizar as médias das leituras de modo a prover uma curva de calibração que representasse o nível de umidade do solo lido, mas sem desconsiderar os fatores atuantes dos substratos analisados. Também se optou por realizar a calibração dos sensores de umidade de solo com base em porcentagens do nível máximo de saturação, considerando que durante a coleta de dados no cano a umidade provavelmente se aproximará ao de saturação.

Utilizou-se o método padrão de estufa para validar a correlação entre a umidade obtida pelo método padrão e a leitura feita pelos sensores de umidade de solo. Para cada amostra e nível de saturação do solo foram realizadas três medições para obtenção de uma possível função que representasse essa relação.

A tabela 4 ilustra os dados utilizados para obtenção da umidade da amostra utilizada pelo método padrão de estufa para os níveis de umidade relativos pretendidos de $100 \%$ de saturação.

Para se obter os $100 \%$ de saturação utilizou-se três recipientes plásticos de mesmo volume e dimensões para acomodar um quilo de solo. Pesou-se o recipiente para obter sua tara e um quilo de solo seco. Adicionou-se lentamente água até que o solo apresentasse aspecto de saturação com uma fina lâmina de água na superfície e superfície brilhante. Neste momento media-se a quantidade restante de água da inicial, de 1 litro, e pesava-se o recipiente com o solo úmido.

Se no período de meia hora o solo permanecesse com o mesmo aspecto, o volume em mililitros utilizado era anotado para servir como referência para o necessário para atingir o nível de saturação desejado. Caso, nesse período, fosse necessário adicionar água, aguardava-se meia hora novamente.

Tabela 4 - Tabela ilustrando as médias de umidade dos níveis de saturação obtidas pelo método padrão de estufa para as três texturas estudadas

\begin{tabular}{|l|l|l|l|}
\hline $\begin{array}{l}\text { Nível de saturação } \\
(\%)\end{array}$ & $\begin{array}{l}\text { Muito argilosa } \\
(\%)\end{array}$ & $\begin{array}{l}\text { Argilosa } \\
(\%)\end{array}$ & $\begin{array}{l}\text { Média } \\
(\%)\end{array}$ \\
\hline 20 & 8,41 & 8,76 & 5,49 \\
\hline 40 & 16,05 & 14,17 & 11,43 \\
\hline 60 & 22,13 & 22,01 & 16,27 \\
\hline 80 & 32,13 & 30,08 & 24,27 \\
\hline 100 & 39,53 & 42,1 & 29,76 \\
\hline
\end{tabular}

Na tabela 4 encontram-se as médias dos valores lidos para cada nível percentual de umidade e suas respectivas curvas de calibração para as três texturas analisadas: muito argilosa, argilosa e média. Os valores médios de porcentagem de umidade foram obtidos pela média da porcentagem de umidade das amostras extraídas quando da calibração dos sensores e a média das leituras dos sensores pelo valor médio lido pelos sensores em cada faixa de umidade.

As figuras 10 a 12 ilustram as linhas de tendência geradas pela média dos valores lidos pelos sensores de umidade aos níveis de $0,20,40,60,80$ e 100\% de saturação (eixo X) e a umidade obtida pelo método padrão de estufa para os mesmos níveis (eixo y) para cada textura de solo estudada.

A figura 10 mostra a linha de tendência para a textura muito argilosa como sendo linear e tendo R2, coeficiente de determinação, bastante alto, 0,9034, e, coeficiente de correlação, 0,9504, indicando uma forte correlação positiva apesar de sua equação $(0,0408 * x+7,0984)$ subestimar valores perto de $15 \%$ de umidade e superestimar valores perto de $25 \%$ de umidade. As leituras para os outros níveis de umidade fornecem valores perto dos reais obtidos por método padrão de estufa.

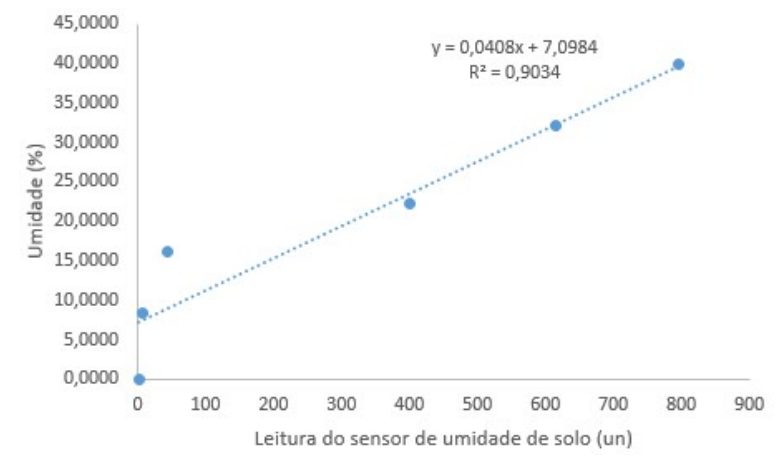

Fig. 10 Gráfico de dispersão dos sensores para a textura muito argilosa e sua respectiva equação linear obtida em laboratório

Embora a linha de tendência obtida para a textura argilosa, ilustrada na figura 11, tenha tido um R2 alto, 0,8692, e forte coeficiente de correlação positiva, de 0,9338 , a equação obtida superestima os valores de umidade para as leituras feitas para os níveis de saturação de umidade de 20, 40 e 100\% e subestima para 60 e $80 \%$.

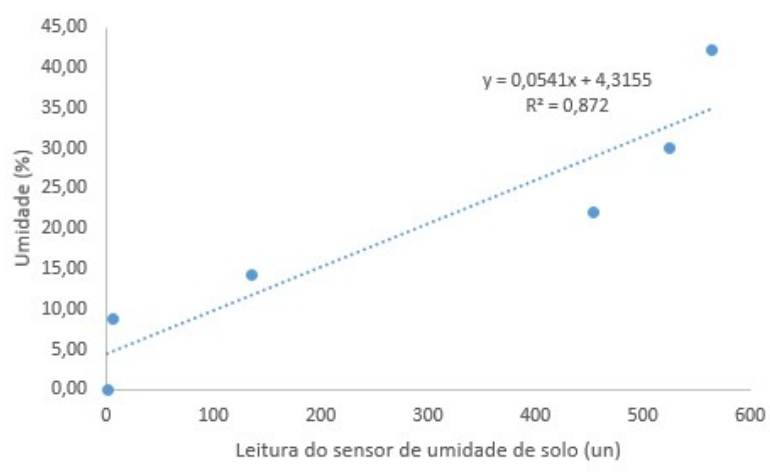

Fig. 11 Gráfico de dispersão dos sensores de umidade de solo com sua respectiva equação linear, obtida em laboratório, para a textura argilosa

De modo similar a linha de tendência da textura argilosa, a equação obtida pela linha de tendência para a textura média e ilustrada na figura 12 tende a superestimar as porcentagens de umidade para os níveis de saturação de 20,80 e 100 e subestimar os níveis 40 e 60 . 


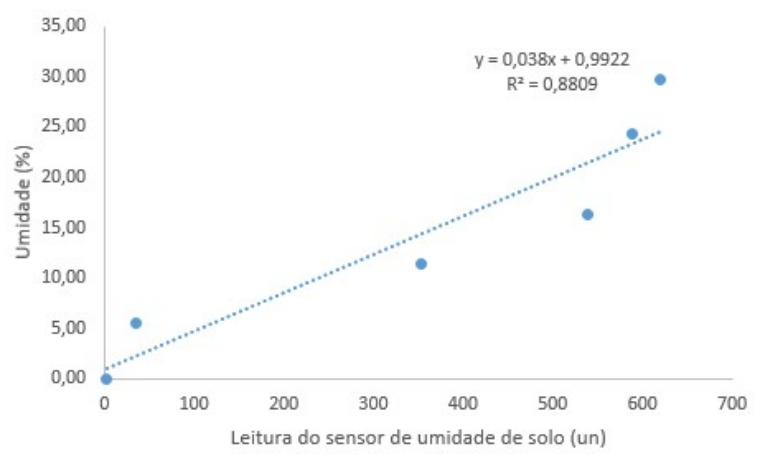

Fig. 12 Gráfico de dispersão dos sensores de umidade do solo com suas respectivas equações lineares, obtida em laboratório, para a textura média

Nota-se que os valores de R2 para as três texturas foram elevados, apresentando valores de 0,9034 para a muito argilosa, 0,8692 para a argilosa, e 0,8809 para a média. Outras linhas de tendência foram testadas e embora também tenham resultado em R2 altos, as linhas mostradas resultaram em coeficientes de determinação (R2) superiores.

\section{CONCLUSÃo}

O objetivo deste trabalho foi apresentar o desenvolvimento e calibração de uma solução IoT para medição de infiltração e retenção hídrica nos três solos estudados. Não foi encontrada alteração nas medições na umidade e temperatura (entre 22 e $26^{\circ} \mathrm{C}$ ) ambientes quando da calibração.

O ambiente de desenvolvimento utilizado não apresentou problemas durante o período de testes, mostrando-se uma alternativa interessante para desenvolvimento de aplicações IoT variadas.

As leituras obtidas com os sensores de umidade de solo foram imprecisas, porém aceitáveis especialmente considerando o custo de sua fabricação, por volta de 5 reais a unidade.

A solução implementada mostrou-se bastante estável já que não foi necessária intervenção no período de calibração.

\section{REFERÊNCIAS}

[1] MitTELBACH, H., Lehner, I., Seneviratne, S.I., 2012. Comparison of four moisture sensor types under field conditions in Switzerland. Journal od Hydrology 430-431, 39-49. Skill in streamflow forecasts derived from large-scale estimates of soil moisture and snow. Nat. Geosci. 3 (9), 613-616.

[2] SENEVIRATNE, S.I., Corti, T., Davin, E., Hirschi, M., Jaeger, E.B., Lehner, I., Orlowsky, B., Teuling,
A.J., 2010. Investigating soil moisture-climate interactions in a changing climate. Earth-Sci. Rev. 99 (3-4), 125-161.

[3] Agência Nacional das Águas - ANA, Relatório da ANA apresenta situação das águas do Brasil no contexto de crise hídrica. Disponível em: http://www3.ana.gov.br/portal/ANA/noticias/relator io-da-ana-apresenta-situacao-das-aguas-do-brasilno-contexto-de-crise-hidrica. Acesso em: 20 fevereiro 2019

[4] MAPA - Ministério da Agricultura, Pecuária e Abastecimento. Projeções do agronegócio brasil 2011-2012 a 2021-2022 síntese. 2012. Disponível em: http://www.agricultura.gov.br/assuntos/politicaagricola/todas-publicacoes-de-politicaagricola/projecoes-do-agronegocio/projecoes-doagronegocio-brasil-2011-2012-a-2021-2022sintese.pdf. Acesso em: 27 maio 2018

[5] MANTOVANI et al, Irrigação: princípios e métodos, $3^{\mathrm{a}}$ edição, 2009

[6] SILVA, C. R.; ANDRADE JÚNIOR, A. S.; SOUZA, C. F. Aspectos práticos na utilização da técnica de capacitância: desafios e aprendizagem. Aplicações de Técnicas eletromagnéticas para o monitoramento ambiental, v. 1, p. 25-45, 2008

[7] PIZETTA, S. C. Calibração de sensores de capacitância (FDR) para estimativa da umidade em diferentes solos. Universidade Federal de Lavras, 2015 .

[8] KINZLI, K.; MANANA, N.; OAD, R. A comparison of laboratory and field calibration of a soil moisture capacitance probe for various soils. Journal of Irrigation and Drainage Engineering, v. 138, n. 4, p. 310-321, 2012.

[9] SPELMAN, D.; KINZIL, K-D.; KUNBERGER, T. Calibration of the 10HS Soil Moisture Sensor for Southwest Florida Agricultural Soils. Journal of Irrigation and Drainage Engineering, v. 139, n. 12, p. 965-971, 2013.

[10] PREVEDELLO, C.L., LOYOLA, J.M.T., Modelagem numérica para o processo da evaporação da água do solo, Revista Brasileira de Ciência de solo, 29:669-675, 2005 